\title{
MODIFIKASI HURUF KATAKANA PESAN MENGGUNAKAN METODE ADVANCE VIGENERE CIPHER
}

${ }^{1}$ Adrian Muhammad yusuf, Diana ${ }^{2}$

${ }^{12}$ Universitas Muhammadiyah Bengkulu, Indonesia 1.pgmadrian18@gmail.com, 2 diana@umb.ac.id

\section{Article Info}

\section{Article history:}

Received, 3/11/2020

Revised, 19/11/2020

Accepted, 1/12/2020

\section{Kata Kunci:}

pascapanen

limbah_pertanian

pertanian

sosialisasi

motion_graphic

\begin{abstract}
ABSTRAK
Kriptografi adalah suatu bidang ilmu dan seni yang bertujuan untuk menjaga kerahasiaan suatu pesan yang berupa data-data dari pihak lain yang tidak berhak sehingga tidak menimbulkan kerugian. seiring dengan majunya perkembangan dunia pemrograman, teknik dasar Vigenere Cipher dapat sedikit dimodifikasi sehingga tidak hanya mampu melakukan enkripsi terhadap karakter alphabet, namun juga angka dan simbol khusus. Dengan menerapkan metode AVC sebagai metode pengamanan informasi pesan, probabilitas intruder untuk memecahkan kode enkripsi sistem dapat ditekan secara optimal. maka rumusan masalah bagaimana penerapan modifikasi huruf katakana dalam pengaman pesan menggunakan metode advance vigenere cipher. Tujuan penelitian ini adalah untuk membuat aplikasi modifikasi huruf katakana dalam pengaman pesan menggunakan metode advance vigenere cipher. Adapun manfaat penelitian ini untuk memberikan informasi pesan plainteks menjadi chiperteks berdasarkan kata kunci, sehingga pesan dapat terjaga kerahasiannya. Teknik pengumpulan data yang digunakan dalam penelitian ini observasi dan studi pustaka. Diharapkan pengembangan aplikasi ini dapat menjadi referensi bukan hanya dunia perbankan juga untuk semua kalangan sebagai perkemangan informasi teknologi.
\end{abstract}

\section{ABSTRACT}

Cryptography is a field of science and art that aims to maintain the confidentiality of a message in the form of data from other unauthorized parties so as not to cause harm. As the world of programming advances, the basic technique of the Vigenere Cipher can be slightly modified so that it is not only able to encrypt alphabetic characters, but also special numbers and symbols. By implementing the AVC method as a method of securing message information, the probability of an intruder to crack the system encryption code can be optimally suppressed. then the formulation of the problem of how to apply the katakana letter modification in message security using the advanced vigenere cipher method. The purpose of this study was to make an application to modify the katakana letter in message security using the advanced vigenere cipher method. The benefit of this research is to provide plaintext message information into ciphertext based on keywords, so that the confidentiality of messages can be maintained. Data collection techniques used in this study were observation and literature study. It is hoped that the development of this application can become a reference not only for the banking sector but also for all groups as a development of information technology.

This is an open access article under the CC BY-SAlicense.

\footnotetext{
Penulis Korespondensi:

Diana,

Program Studi Informatika,

Universitas Muhammadiyah Bengkulu,

Email: diana@umb.ac.id
} 


\section{PENDAhuluan}

Kriptografi atau yang sering dikenal dengan sebutan ilmu penyandian data adalah suatu bidang ilmu dan seni yang bertujuan untuk menjaga kerahasiaan suatu pesan yang berupa data-data dari pihak lain yang tidak berhak sehingga tidak menimbulkan kerugian [1][2]. Pada masa sekarang ini, kriptografi atau ilmu penyandian data sering diklasifikasikan menjadi dua jenis yaitu kriptografi klasik dan kriptografi modern [3][4].

Kriptografi klasik sudah mulai dipelajari manusia sejak tahun 400 SM, yaitu pada zaman Yunani kuno. Kriptografi klasik ini lebih menekankan pada perubahan tiap karakter dalam upaya menjaga kerahasiaan pesan. Sedangkan kriptografi modern lebih menekankan pada pengoperasian bit-bit. Pada kriptografi klasik terdapat 2 algoritma, yaitu cipher substitusi dan cipher transposisi [5][6][7].

Vigenere chiper merupakan salah satu algoritma kriptografi klasik untuk menyandikan suatu plaintext dengan menggunakan teknik substitusi [3][8][9]. Seiring dengan majunya perkembangan dunia pemrograman, teknik dasar Vigenere cipher dapat sedikit dimodifikasi sehingga tidak hanya mampu melakukan enkripsi terhadap karakter alphabet, namun juga angka dan simbol khusus.

Salah satu hal yang paling penting dalam komunikasi menggunakan komputer dan jaringan komputer adalah untuk menjamin keamanan pesan, data, atau informasi dalam pertukaran data, sehingga menjadi salah satu pendorong munculnya teknologi kriptografi [2][10][11]. Algoritma kriptografi berdasarkan data pengkodean informasi yang mendukung kebutuhan dua aspek keamanan informasi, yaitu kerahasiaan (perlindungan kerahasiaan data informasi) dan keaslian Dalam pembuatan aplikasi kriptografi ini, metode yang digunakan adalah Vigenere Cipher, salah satu bentuk lain dari enkripsi jenis poly abjad. Aplikasi dibuat dengan perangkat lunak Visual Basic 6.0 dan pembuatan aplikasi dengan enkripsi diharapkan untuk mengatasi permasalahan tersebut [12][13].

Implementasi Algoritma Kriptografi Kunci Publik Elgamal Untuk Proses Enkripsi Dan Deskripsi Guna Pengamanan File Data. Subyek dalam penelitian ini adalah bagaimana mengamankan sebuah file data. Metode yang digunakan adalah Kriptografi ElGamal metode ini merupakan bagian dari kriptografi asimetris Algoritma ElGamal terdiri dari tiga proses, yaitu proses pembentukan kunci, proses enkripsi dan proses dekripsi ("implementasi algoritma kriptografi kunci publik elgamal untuk proses enkripsi dan dekripsi guna pengamanan file data," 2014).

Algoritma ini merupakan cipher blok, yaitu melakukan proses enkripsi pada blok-blok plainteks dan menghasilkan blok-blok cipherteks yang kemudian dilakukan proses dekripsi dan hasilnya digabungkan [14][15]. Keamanan algoritma ElGamal terletak pada kesulitan penghitungan logaritma diskret pada bilangan modulo prima yang besar sehingga upaya untuk menyelesaikan masalah logaritma ini menjadi sangat sukar. Sistem yang dihasilkan diuji dengan dua metode, yaitu Black Box Test dan Alpha Test.

\section{METODE PENELITIAN}

A. Metode pengumpulan data

Untuk penerapan modifikasi metode advance vigenere cipher dalam pengaman pesan untuk menerapkan metode AVC sebagai metode pengamanan informasi pesan. Teknik pengumpulan data yang digunakan dalam penelitian ini adalah sebagai berikut :

1. Observasi

Dalam hal ini observasi dilakukan secara formal maupun informal untuk mengamati secara kualitatif berbagai kegiatan dan peristiwa yang terjadi. Dalam penelitian ini perlu dilakukan observasi untuk memperoleh data atau informasi yang lebih spesifik tentang format dalam notifikasi pesan email.

2. Studi Pustaka

Studi Pustaka yaitu pengumpulan data yang besumber dari arsip/dokumen yang bersumber dari buku kepustakaan, hasil penelitian dan arsip atau dokumen yang berhubungan dengan penelitian ini. 
JSAI : Journal Scientific and Applied Informatics

Vol. 3, No. 3, November 2020, hal. 156 162

E-ISSN: 2614-3054; P-ISSN: 2614-3062, accredited by Kemenristekdikti, Sinta 5

DOI: 10.36085

\section{B. Desain}

Rancangan aplikasi atau desain aplikasi akan disesuaikan dengan data yang telah dikumpulkan pada tahap sebelumnya. Rancangan aplikasi ini akan dimulai dengan Tabel Vigenere setelah itu Tabel Modifikasi Advance Vigenere seperti dibawah ini.

\section{Tabel Vigenere}

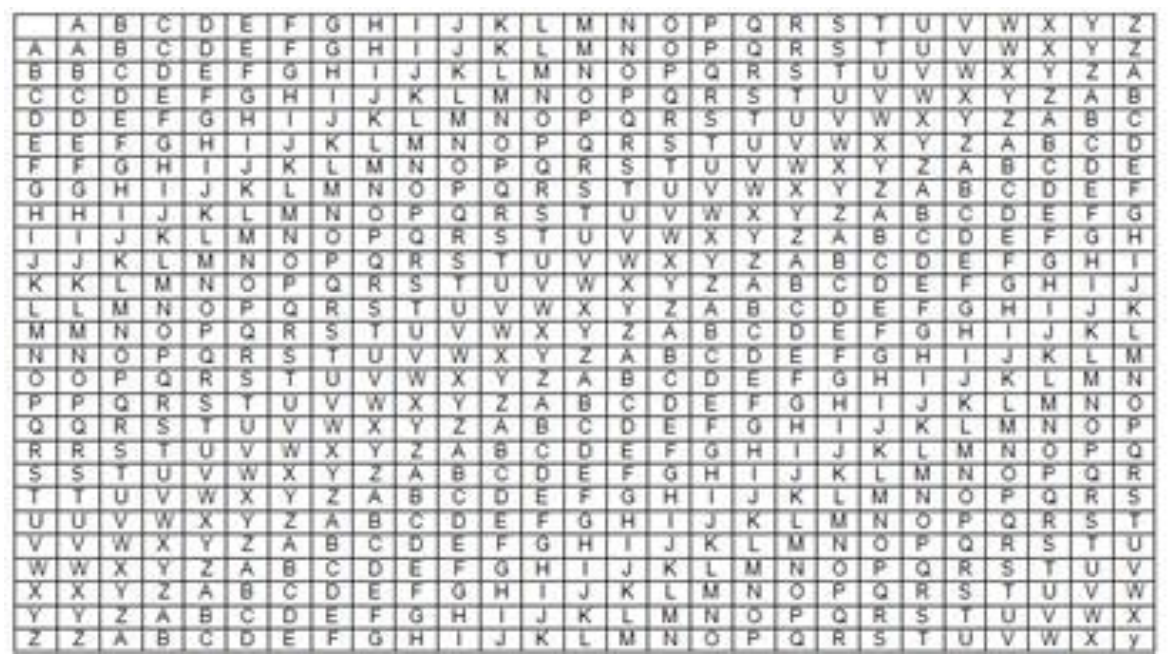

Var alphabet $=$

"ABCDEFGHIJKLMNOPQRSTUVWXYZ" + "abcdefghijklmnopwrstuvwxyz";

2. Tabel Modifikasi Advance Vigenere

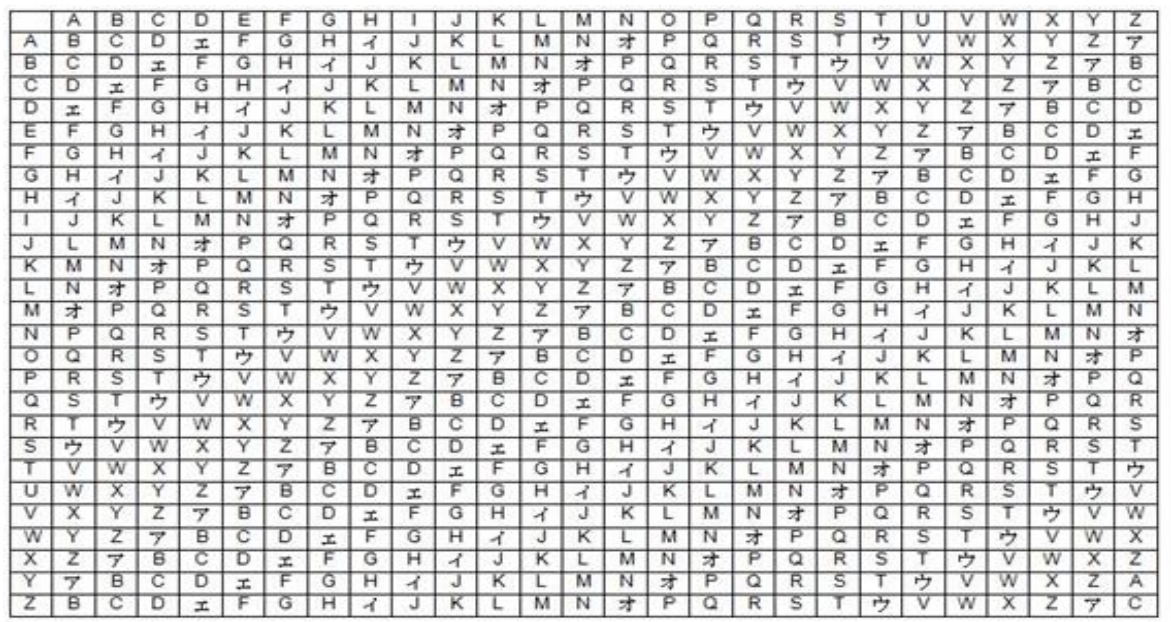

Adapun contoh model matematika dari enkripsi pada algoritma advance Vigenère cipher ini adalah seperti berikut : Plainteks adalah muhammadiyah

Kunci : alfareno

Hasil : musarmaウicaウ

3. Diagram Konteks

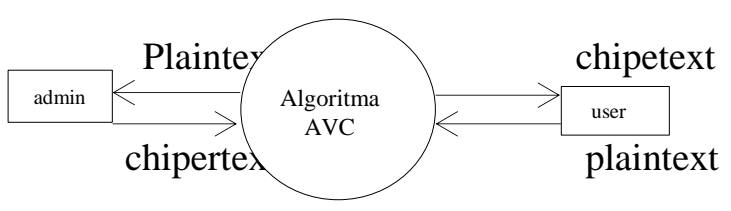

Gambar 3 Diagram Konteks

Berdasarkan gambar 3.2 diatas, admin memberikan plainteks kepada sistem AVC kemudian sistem memberikan chiperteks kepada admin. Sedangkan user mengirim chiperteks kepada sistem AVC, dan sistem AVC memberikan plainteks kepada user. 
JSAI : Journal Scientific and Applied Informatics

Vol. 3, No. 3, November 2020, hal. 156 162

E-ISSN: 2614-3054; P-ISSN: 2614-3062, accredited by Kemenristekdikti, Sinta 5

DOI: 10.36085

\section{Rancangan Enkripsi}

Rancangan enkripsi merupakan penguncian file, adapun rancangan enkripsi dapat dilihat pada gambar 4.

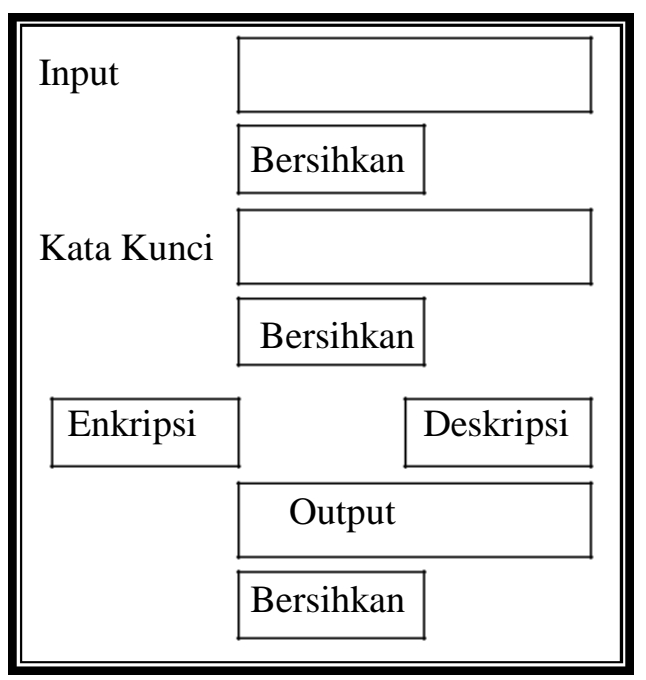

Gambar 4 Rancangan Enkripsi

5. Code

Pada tahap ini merupakan desain yang telah ditetapkan kedalam bahasa pemrograman yang dimengerti komputer. Dalam penelitian ini bahasa pemrograman yang akan digunakan adalah $P H P$ dan MySQL.

6. Test

Rancangan pengujian sistem dilakukan setelah penerapan modifikasi metode andvance vigenere cipher dalam pengaman pesan yang dibuat telah selesai. Proses pengujian sistem dilakukan dengan cara Black-Box memfokuskan pada keperluan fungsional dari aplikasi ini. Pengujian ini digunakan untuk menguji apakah semua kebutuhan atau requirement fungsional terpenuhi.

\section{HASIL DAN ANALISIS}

\section{A. Hasil}

Adapun hasil penelitian aplikasi modifikasi huruf katakana dalam pengaman pesan menggunakan metode vigenere cipher adalah sebagai berikut :

1. Tampilan Enkripsi

Pada tampilan enkripsi, akan mengenkripsi file dan kemudian akan muncul box dialog nama dan password sebagai enkripsi keamanan. Adapun tampilan enkripsi, dapat dilihat pada gambar 1.1.

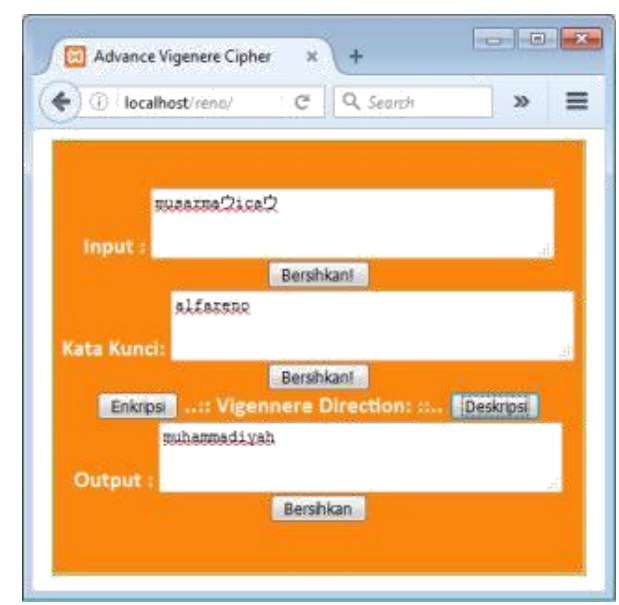

Gambar 1.1 Tampilan Enkripsi 
Berdasarkan gambar 1.1 diatas, plainteks adalah saldo_anda, kata kunci reno, maka chiperteks adalah japwo_ab?a. Adapun cara mendapatkan hasil chiperteks adalah sebagai berikut : Plainteks : muhammadiyah

Kunci : alfareno

Chiperteks : :musarmaウicaウ

2. Tampilan Deskripsi

Tampilan deskripsi merupakan penguncian file, adapun tampilan deskripsi dapat dilihat pada gambar 2.1.

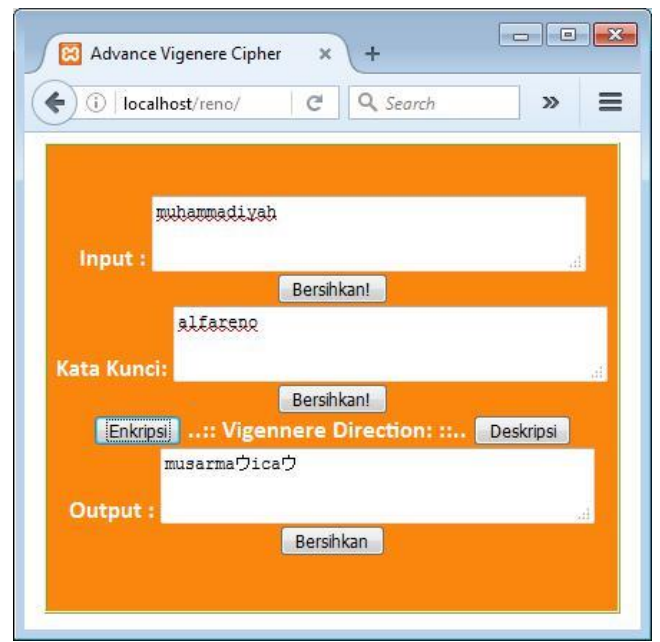

Gambar 2.1 Tampilan Deskripsi

Berdasarkan gambar 2.1 diatas, tampilan deskripsi merupakan kebalikan dari langkah enkripsi, adapun langkah deskripsi adalah sebagai berikut :

Chiperteks : musarmaウicaウ

Kunci : alfareno

Plainteks : muhammadiyah

Adapun coding deskripsi adalah sebagai berikut :

if (lowercase)

input_char_value $=$ input_char_value $\% 26+26$; else

input_char_value $\%=26$;

output $+=$ alphabet. charAt (input_char_value $) ;$ key_index $=($ key_index +1$) \%$ key_len;

\}

return output;

\section{B. Pembahasan} berikut:

Dalam pembahasan aplikasi advance vigenere cipher dalam pengaman pesan adalah sebagai

1. Menentukan tampilan aplikasi

Dalam pembuatan aplikasi menggunakan bahasa pemogram PHP dengan editor dreamweaver. Membuat input sebagai plainteks, kata kunci dan output sebagai chiperteks. Dimana terdapat 2 buah button yaitu enkripsi dan deskripsi. Menentukan variabel dalam coding, supaya tabel vigenere chiper dapat terbentuk dalam aplikasi, adapun tabel vigenere chiper adalah sebagai berikut 
JSAI : Journal Scientific and Applied Informatics

Vol. 3, No. 3, November 2020, hal. 156 162

E-ISSN: 2614-3054; P-ISSN: 2614-3062, accredited by Kemenristekdikti, Sinta 5

DOI: 10.36085

Var alphabet $=$

"ABCDEFGHIJKLMNOPQRSTUVWXYZ"

"abcdefghijklmnopwrstuvwxyz";

2. Melakukan modifikasi dari tabel vigenere chiper dengan cara merubah tabel dalam coding aplikasi dengan menggunakan tipe sistem 32bit, adapun perubahan tabel adalah sebagai berikut :

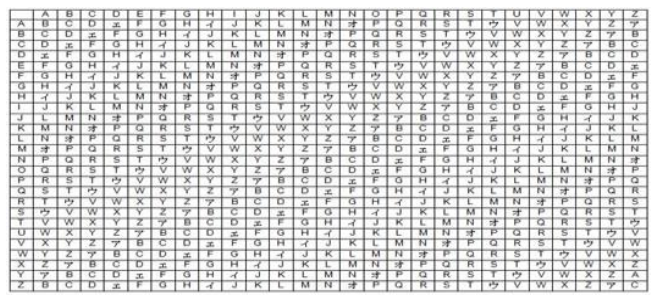

Var alphabet $=$

"ABCDEFGHIJKLMNOPQRSTUVWXYZ"

“アbcdIfghイjklmnオpwrst门vwxyz";

3. Pengujian Sistem

Dari hasil pengujian sistem baru ini, maka penulis menyimpulkan bahwa dengan adanya aplikasi ini akan memberikan pengaman pesan. Adapun hasi pengujian dilihat pada tabel dibawah ini:

a. Whitebox Testing
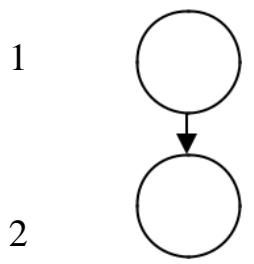

\section{Gambar a Graph Whitebox Testing}

Berdasarkan graph diatas, merupakan penjelasan dari pengujian Whitebox Testing adalah sebagai berikut :

1. Jika kata plainteks dan kata kunci ada maka hitung jumlah variabel alphabet

2. Jika kata kunci lebih kecil dari 1 karakter alphabet maka akan muncul pesan "kamu lupa ya".

b. Blackbox Testing

Tabel b Hasil Pengujian Sistem Black Box

\begin{tabular}{|c|c|c|c|}
\hline $\begin{array}{l}\text { Proses } \\
\text { yang diuji }\end{array}$ & $\begin{array}{l}\text { Skenario } \\
\text { Pengujian }\end{array}$ & $\begin{array}{l}\text { Hasil yang } \\
\text { diharapkan }\end{array}$ & $\begin{array}{l}\text { Hasil } \\
\text { pengujian }\end{array}$ \\
\hline $\begin{array}{l}\text { Tampilan } \\
\text { Enkripsi }\end{array}$ & $\begin{array}{l}\text { Tulis pesan dan } \\
\text { masukkan kata } \\
\text { kunci maka akan } \\
\text { keluar hasil } \\
\text { enkripsi }\end{array}$ & $\begin{array}{l}\text { Akan } \\
\text { muncul } \\
\text { pesan-pesan } \\
\text { yang telah } \\
\text { terenkripsi }\end{array}$ & $\begin{array}{l}\text { Dapat } \\
\text { dilihat } \\
\text { gambar a }\end{array}$ \\
\hline $\begin{array}{l}\text { Tampilan } \\
\text { Deskripsi }\end{array}$ & $\begin{array}{lr}\text { Tulisan } & \text { pesan } \\
\text { enkripsi } & \text { dan } \\
\text { masukkan } & \text { kata } \\
\text { kunci maka akan } \\
\text { keluar } & \text { hasil } \\
\text { deskripsi } & \\
\end{array}$ & $\begin{array}{l}\text { Akan } \\
\text { muncul } \\
\text { pesa-pesan } \\
\text { asli }\end{array}$ & $\begin{array}{l}\text { Dapat } \\
\text { dilihat } \\
\text { pada } \\
\text { gambar b }\end{array}$ \\
\hline
\end{tabular}




\section{KESIMPULAN (11 PT)}

1. Hasil penelitian ini untuk membuat aplikasi advance vigenere cipher dalam pengaman pesan.

2. Advance Vigenere Cipher (AVC) merupakan metode enkripsi serupa dengan Pure Vigenere, namun memiliki kemampuan untuk melakukan enkripsi terhadap berbagai macam karakter selain karakter alphabetik. AVC dapat diterapkan sebagai metode enkripsi pada sistem keamanan pesan

3. Dari hasil pengujian sistem baru ini, aplikasi ini akan memberikan pengaman pesan.

\section{REFERENSI}

[1]. Bekti, H. B. (2015). Mahir Membuat Website Dengan Adobe Dreamweaver CS6, CSS, Dan Jquery. AndiPublisher.

[2]. Efrand, Asnawati, Y. (2014). Aplikasi Kriptografi Pesan Menggunakan Algoritma Vigenere Cipher. Jurnal Media Infotama.

[3]. Husodo, A. yudo. (2010). Penerapan Metode Enkripsi Vigenere Cipher dalam Pengamanan Transaksi Mobile Banking. MAKALAH IF3058 KRIPTOGRAFI.

[4]. IMPLEMENTASI ALGORITMA KRIPTOGRAFI KUNCI PUBLIK ELGAMAL UNTUK PROSES ENKRIPSI DAN DEKRIPSI GUNA PENGAMANAN FILE DATA. (2014). JSTIE (Jurnal Sarjana Teknik Informatika) (E-Journal). https://doi.org/10.12928/jstie.v2i2.2845

[5]. Mustakini, J. H. (2009). Sistem Informasi Teknologi. Yogyakarta: Andi Offset.

[6]. Ramadhani, S., Anis, U., \& Masruro, S. T. (2013). Rancang Bangun Sistem Informasi Geografis Layanan Kesehatan Di Kecamatan Lamongan Dengan PHP MySQL. Jurnal Teknika.

[7]. Zelviana, A., Efendi, S., \& Dedy, A. (2012). Perancangan Aplikasi Pembelajaran Kriptografi Kunci Publik ElGamal Untuk Mahasiswa. Jurnal Dunia Teknologi Informasi.

[8]. Berita Satu, "Teknologi Enkripsi, Solusi Terbaik Pengamanan Data," [Online]. Available: http://www.beritasatu.com/iptek/426799-teknologi-enkripsisolusi-terbaik-pengamanan-data.html. [Accessed 29 November 2018].

[9]. Humaira, Rafiqa, dkk "Kriptanalisis dengan Metode Brute Force pada Graphics Processing Unit", Hal. $2-5$, Bandung

[10]. F. D. Paliama, "Perancangan Kriptografi Block Cipher Berbasis Pada Teknik Formasi Permainan Bola Perancangan Kriptografi Block Cipher Berbasis Pada Teknik Formasi Permainan Bola," Universitas Kristen Satya Wacana, 2016.

[11]. N. M. Louhenapessy, "Perancangan Kriptografi Block Cipher Berbasis Pola Formasi Futsal 1-2-1," Universitas Kristen Satya Wacana, 2016.

[12]. B. L. Setiyadi, “ Perancangan Kriptografi Block Cipher Berbasis Pada Pola Gerakan Lempeng Tektonik Divergensi dan Konvergensi Program Studi Tenik Informatika Fakultas Teknologi Informasi Universitas Kristen Satya Wacana Salatiga Movember 2016 Perancangan Kriptografi Block, “ Universitas Kristen Satya Wacana, 2016.

[13]. Mahendra, Dwi Putera. 2016. Perancangan Kriptografi Block Cipher Menggunakan Pola Game SUDOKU. Universitas Kristen Satya Wacana: Salatiga.

[14]. K. D. Cahyono, " Perancangan Kriptografi Block Cipher dengan Langkah Permainan Engklek, “ Universitas Kristen Satya Wacana, 2016.

[15]. Munir, R., 2006. Kriptografi. Bandung: Informatika 